\title{
ESTUDO PETROGRÁFICO DAS ROCHAS ÍGNEAS ALCALINAS DA REGIÃO DE LAGOA FORMOSA, MG
}

\author{
HILDOR JOSÉ SEER* e LÚCIA CASTANHEIRA DE MORAES*
}

\begin{abstract}
PETROGRAPHICAL STUDY OF ALKALINE IGNEOUS ROCKS OF LAGOA FORMOSA REGION, MG. The first results of a petrographic study about the alkaline rocks from Lagoa Formosa region, Minas Gerais, Brazil, are presented. The rocks belong to the Cretaceous Mata da Corda Formation of the Săo Francisco Basin comprising volcanic breccias, lapillites, tuffs, cinerites, lava flows, volcanic pipes, and dykes. The related petrographic terms are mela-leucitites and minor sienites, alkalipyroxenite, and basalt. Generally, the rocks are porphyritic, mafic with olivine, phologopite and pyroxene phenocrysts in a pyroxene, leucite, phlogopite afanitic matrix.
\end{abstract}

INTRODUÇÃO Por ser portador de diamantes e platina (Eschwege 1979, Barbosa 1970), e gerador de excelente solo para agricultura (Guimarães 1927, 1955), o vulcanismo alcalino cretácico da bacia são-franciscana tem despertado o interesse de vários pesquisadores. Foi objeto, por exemplo, de estudos petrográficos de Rimann (1917), Guimarães $(1927,1955)$ e Barbosa (1936) entre outros. Rimann (op. cit.) indica a existencia de kimberlitos associados ao vulcanismo. Por outro lado, Barbosa (1936) e Guimarães (1955) concluem tratar-se de rochas intermediárias, básicas e ultrabásicas alcalinas que localmente se aproximam de um picrito porfiŕtico sem anfibólio s6́dico. Apesar de sua importância, estas contribuiçōes restringiram-se à caracterização de amostras em perfis aleatórios e até o momento não se tem notícia de trabalho sistemático de descrição e definição das mesmas.

Este artigo representa os primeiros resultados petrográficos obtidos a partir de um mapeamento de semidetalhe da região de Lagoa Formosa - porção meridional da bacia sãofranciscana - iniciado há dois anos por um grupo de professores da UFMG. As rochas estudadas pertencem à Formaçāo Mata da Corda (Costa \& Sad 1968) e assentam-se sobre as rochas sedimentares da Formaçāo Areado (Rimann op. cit., Ladeira \& Brito 1968) ou diretamente sobre metadiamictitos e ard6sias (Seer $e$ t al. 1987). A Figura 1 e um mapa simplificado da região estudada. A estratigrafia desta área foi discutida por Moraes et al. (1986).

DISTRIBUIÇÃO DAS ROCHAS ALCALINAS As rochas vulcânicas alcalinas da região estudada compreendem depósitos piroclásticos, derrames, condutos vulcânicos e diques. Sua distribuição é ampla e ultrapassa os limites do mapa geo16 gico da Figura 1 nos sentidos NW, NE e SE. A seqüência de rochas tem espessura muito variável, nunca excendo os $60 \mathrm{~m}$.

De um modo geral, os termos piroclásticos são dominantes na base da seqüência e cedem lugar aos derrames em seu topo. Todo o conjunto acha-se intensamente intemperizado e em franco processo de erosão; caracteristicamente a erosão delineia um relevo suave nos derrames e tufos, mas acidentado e fortemente ravinado nas brechas e lapillitos.

Os depósitos piroclásticos sảo constituídos de brechas e aglomerados vulcânicos, lapillitos, tufos e cineritos. As brechas e os aglomerados sâo petromíticos e neles predominam os fragmentos de afanitos máficos porfiríticos com quantidades muito subordinadas de sienitos, álcali-piroxenito, basalto, arenitos, siltitos, argilitos, metadiamictitos e ardósias. Formam depósitos maciços, que são tão mais grossos quanto mais próximos se encontram dos condutos vulcânicos, e estâo interestratificados com derrames. Nas porçōes mais grossas foram encontrados fragmentos de atê $1 \mathrm{~m}$ de diâmetro. A matriz das brechas e aglomerados é tufăcea a lapillítica (Prancha 1, Foto 1) e pode ser abundante ou quase inexistente. Invariavelmente, acham-se cimentadas por ze6litas (filipsita, natrolita e chabasita) e/ou calcita.

Lapillitos, tufos e cineritos formam camadas de no máximo $2 \mathrm{~m}$ de espessura e são dominantemente líticos. Acham-se também cimentados por zeólitas e/ou calcita. Dentre os tufos foram encontrados também tufos vítreos e soldados (welded tuff) (Prancha 2, Fotomicrografias 4, 5 e 6).

Os derrames formam camadas finas de espessuras irregulares e raramente superiores a $1 \mathrm{~m}$ (Prancha 1, Fotos 2 e 3). Podem ser ricos em amígdalas e em geral são afaníticos e porfiríticos podendo mostrar estruturas de fluxo.

Os condutos vulcânicos - sempre ressaltados na topografia como morrotes - têm formato circular a ovalado e diâmetro médio de poucas dezenas de metros e estão ora preenchidos por brechas de explosão, ora por lavas, ambos, sem exceção, intensamente hidrotermalizados. A leste e nordeste da vila de Campo do Meio, verificou-se que muitos condutos se alinham segundo uma direção N60W, acompanhando a direção preferencial das fraturas observadas. Já os diques apresentam espessuras de poucos decímetros e ocorrem geralmente nas proximidades dos condutos vulcânicos. Diques ricos em micas e fortemente intemperizados foram observados nas proximidades do Córrego Varjão. Assemelham-se macroscopicamente ao Kimberlito Limeira I, em Minas Gerais.

PETROGRAFIA Como a nomenclatura das rochas feldspatóidicas é muito variada e controvertida, optamos pela de Le Bas (1977) e Streckeisen (1967), que enfatizam critérios baseados no índice de coloração e na natureza dos minerais félsicos.

Devido ao alto grau de alteração hidrotermal e intempérica que afeta essas rochas, só 35 das 220 amostras coletadas permitem um estudo petrográfico mais detalhado e, entre elas, um número reduzido se presta à análise química segura. No entanto, os dados obtidos durante o mapeamento e as observaçōes de amostras semi-alteradas indicam que os espécimes estudados são representativos da área. A maioria dos cristais de feldspatóide das rochas estudadas está alterada para zeólitas e/ou argilominerais e apresentam características de leucita. 


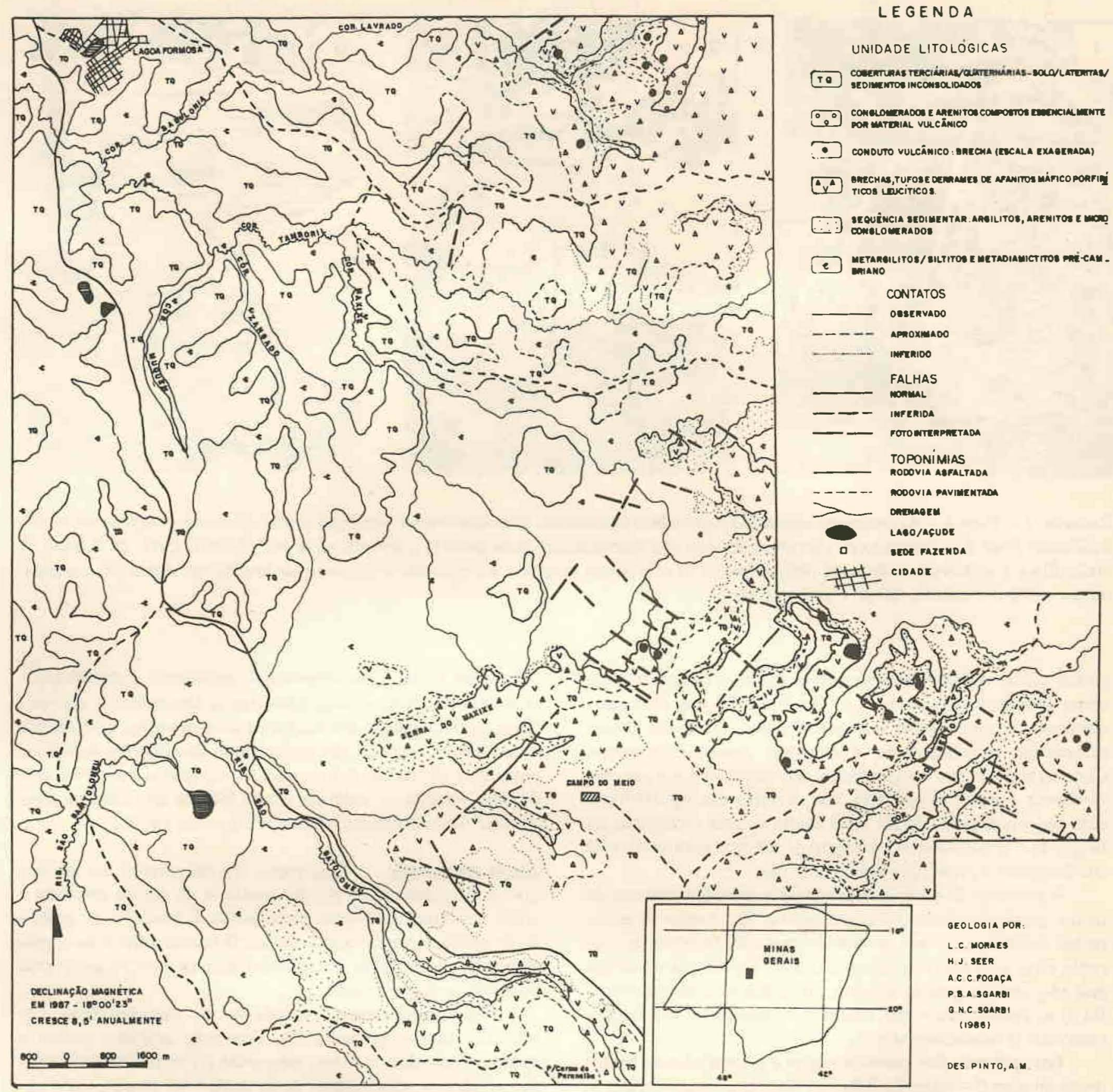

Figura I - Mapa geologico da região de Lagoa Formosa, MG

Ate o momento, as tentativas de caracterização desse mineral por métodos 6 pticos (índice de refração) e por difração de raios $\mathrm{X}$ não permitiram um resultado conclusivo devido a problemas de alteração e/ou à granulometria extremamente fina dessas rochas. Esta questão ê fundamental em vista das recentes discussões sobre lavas cretácicas com analcima primária (Gaspar \& Danni, 1979, Coutinho et al. 1982). Considerando a ausência de picos de analcima e presença de alguns picos de leucita nos difratogramas realizados, os resultados encontrados para índice de refração $(1,498 ; 1,500)$ e os teores relativamente altos de $\mathrm{K}_{2} \mathrm{O}$ nas análises existentes até o momento, optou-se, até segunda ordem, pela designação petrográfica leucititos.
Na tabela 1 é apresentada a composição mineralógica dos tipos ígneos caracterizados; mesmo nos exemplares nos quais não é possível distinguir o feldspatóide na mesóstase os resultados químicos preliminares indicam porcentagem de $\mathrm{K}_{2} \mathrm{O}$ maior que de $\mathrm{Na}_{2} \mathrm{O}$. É importante salientar que esse fato pode, em parte, estar relacionado à presença de flogopita.

No entanto, no atual estágio de conhecimento, essas amostras foram distribuídas nos grupos 1 e 3 da tabela 1 .

Melaleucititos, olivina melaleucititos, flogopita melaleucititos Os termos leucíticos são dominantes entre as rochas vulcânicas e, entre eles, os mais comuns são os melaleucititos. Essas rochas ocorrem como depósitos tufáceos e derrames 

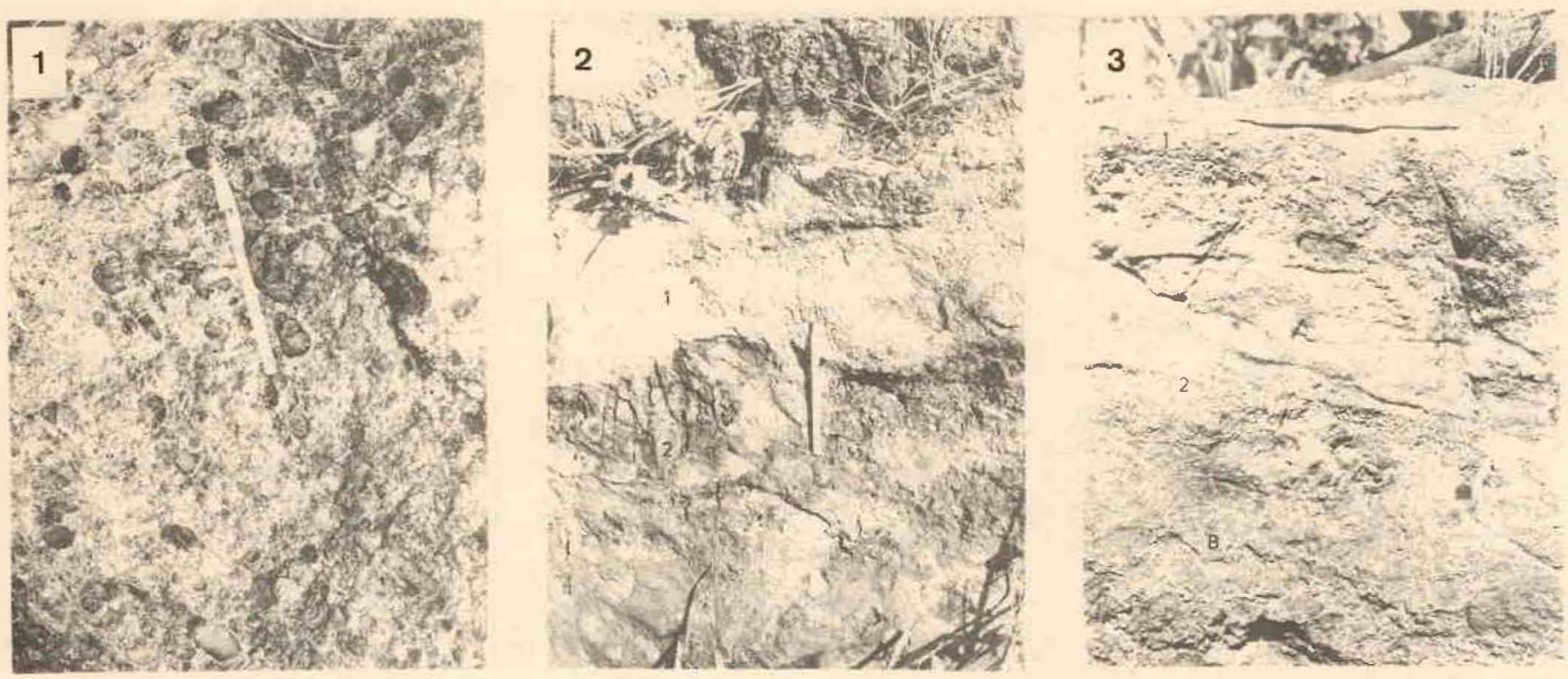

Prancha 1-Foto 1 - Aglomerado vulcânico petromítico constituldo dominantemente por fragmentos de afanitos máficos em matriz lapilltica; Foto 2 - Sucessão de derrames de lava ora intensamente fraturadas (1), ora ricos em amigdalas (2). NE de Campo do Meio; Foto 3 - Derrames de lavas amigdaloidais ( 1 e 2) pouco espessos, sobrepostos a horizonte de brecha vulcânica (B), cimentada por zeolitas e calcita. NE de Campo do Meio

pouco espessos, quase sempre muito intemperizados, e ainda como abundantes fragmentos em brechas e aglomerados piroclásticos, de modo geral bem preservados. Os dados abaixo referem-se principalmente a amostras desses fragmentos. Caracterizam-se por apresentarem estrutura maciça e cor cinza-escura e preta-esverdeada. São afanitos microporfiríticos com fenocristais de olivina e/ou augita e, mais raramente, de flogopita e perovskita. A passagem de um tipo para outro está condicionada à proporção desses minerais.

A presença de olivina restringe-se a microfenocristais, de modo geral corroídos (Fotomicrografia 7). Augita $\varepsilon$ geralmente maclada e zonada, e muitas vezes está fortemente corroída e/ou alterada (Fotomicrografia 8). Os cristais de flogopita sâo, em sua grande maioria, poiquilíticos (Fotomicrografia 9) e, quando não o são, mostram-se zonados e com bordos corroídos (Fotomicrografia 7).

Em qualquer dos casos, a augita é o mineral mais abundante da matriz - exceção feita aos flogopita melaleucititos -, onde forma uma trama microlítica juntamente com leucita, titanomagnetita (?) e perovskita, com flogopita intersticial. Em algumas amostras, os microlitos de augita mostram-se orientados, originando uma textura de fluxo. A leucita forma pequenos cristais euedricos, de modo geral turvos (Fotomicrografia 10). A perovskita pode ser abundante, perfazendo mais de $5 \%$ do volume.

Em algumas dessas rochas foram observados xenólitos ovalados com ate $3 \mathrm{~cm}$ de diâmetro menor. Foram caracterizados dois tipos composicionais: um, com augita, nefelina, olivina, leucita, minerais opacos e perovskita (Fotomicrografia 11); e outro com augita, flogopita, nefelina, minerais opacos e perovskita (Fotomicrografia 12). De um modo geral, esses xenólitos mostram bordos reacionais. Por sua natureza, foram considerados nódulos cognatos.

Alteração hidrotermal pode ser importante e se apresenta na forma de carbonatização, zeolitização, oxidação, desenvolvimento de agulhas de aegirina e transformaçāo de minerais opacos em leucoxênio.
Essas rochas têm mineralogia semelhante à dos flogopita-leucita lamproítos, diopsídio-leucita lamproítos e olivina(flogopita)-diopsídio-leucita lamprof́tos descritos por Jaques et al. (1984), embora não tenham sido descobertos anfibólios potássicos (K-richterita) e minerais acessórios tais como priderita e wadef́ta. A ausência desses últimos aproxima-as mais da suíte Kamafugítica (Sahama in Sorensen 1974).

Álcali-piroxenito Esta rocha foi encontrada em um pequeno afloramento na porção nordeste da regiăo mapeada e como um bloco em brecha piroclástica. É bandada, de granulaçåo média e cor castanho-escura. $O$ bandamento $e$ dado pela disposição dos cristais de clinopiroxênio (augita?) e a cor, pela abundância de perovskita.

Mineralogicamente, compöe-se de clinopiroxênio, perovskita, titano-magnetita (?), flogopita, nefelina, zeólita e apatita. Perovskita e titano-magnetita (?) ocorrem como cristais anédricos e subédricos equivalentes em tamanho aos clinopiroxênios e também inclusos nestes como diminutos cristais. A flogopita é claramente intersticial e sua continuidade optica indica que se trata de grandes cristais poiquilíticos. Zeólita e nefelina ocorrem juntas preenchendo cavidades irregulares que, às vezes, assemelham-se a vênulas (?). A apatita aparece inclusa no clinopiroxênio como cristais anédricos compondo de $5 \%$ a $10 \%$ do volume da rocha. A textura dessa rocha (Fotomicrografias 14 e 15) lembra um cumulado, cujos cristais cúmulus continuaram reagindo com o líquido após assentamento.

É importante notar que, entre as rochas estudadas, somente uma amostra de sienito e os álcali-piroxenitos são portadores de nefelina.

Basalto Esse tipo litológico também ê de ocorrência restrita, aparecendo na forma de raros blocos em brechas piroclásticas. Tem aspecto maciço, cor cinza-escura esverdeada e matriz afanítica, na qual se destacam microfenocristais $(1 \mathrm{~mm})$ de plagioclásio sem qualquer orientação preferencial. 
4

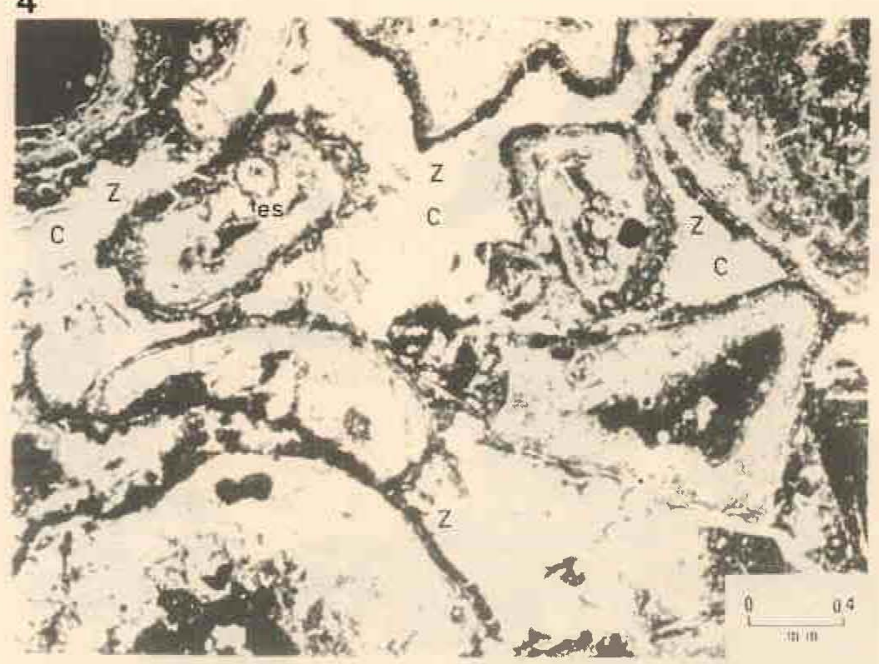

6

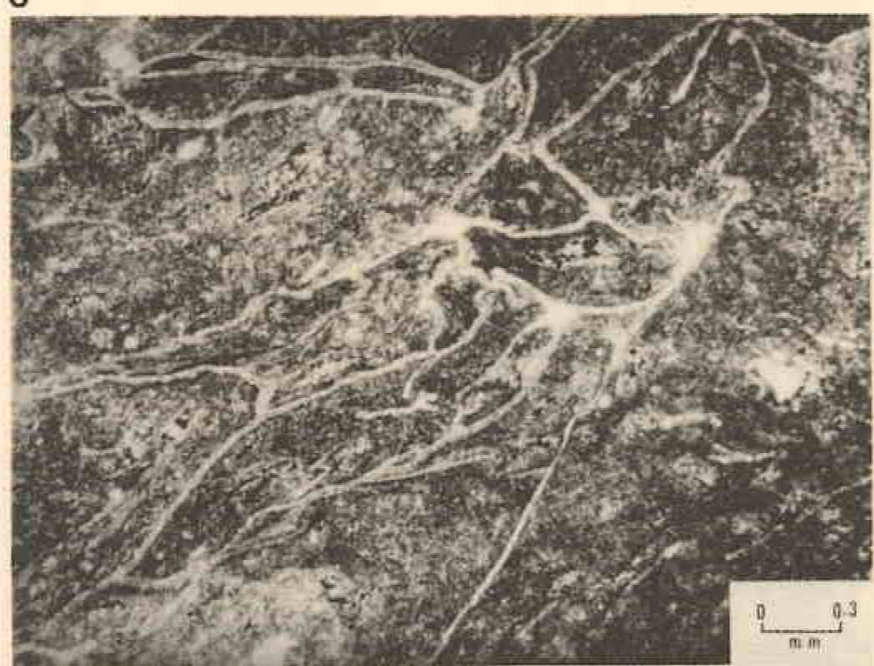

8

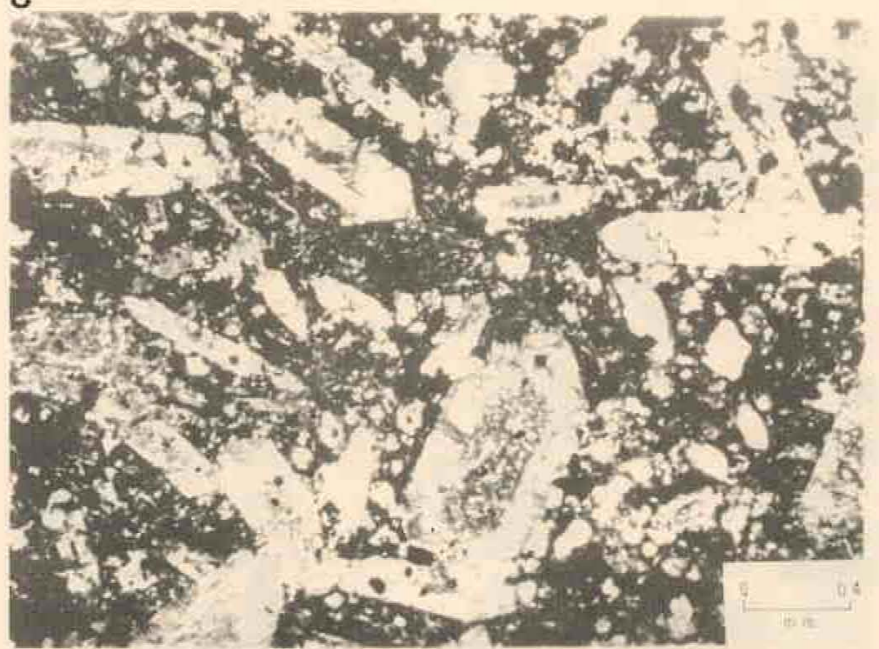

5

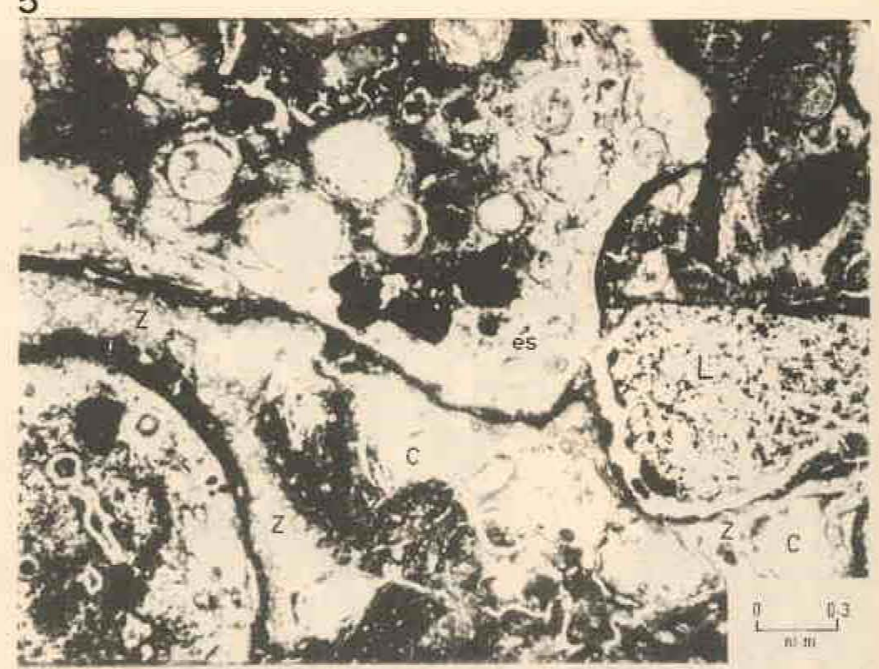

7

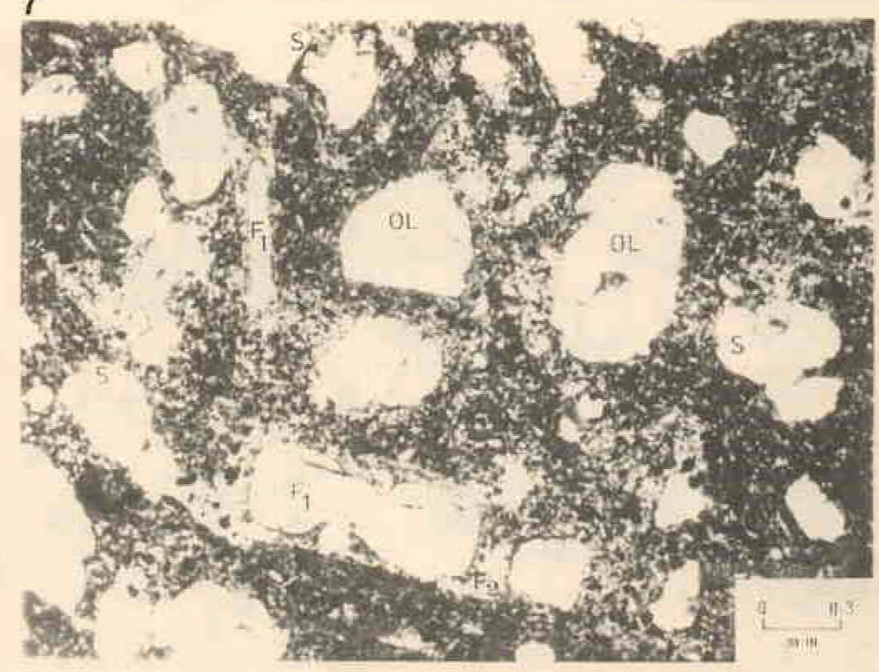

9

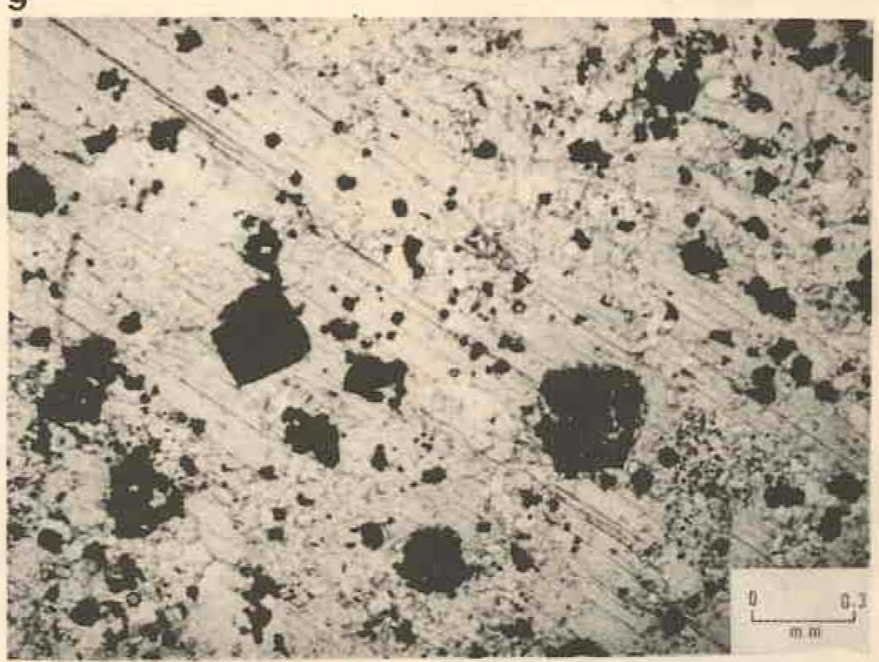

Prancha 2 - Fotomicrografias. 4 - Tufo vítreo composto por fragmentos angulosos de material devitrificado (franjas de clorita esmectita e hidróxidos de ferro), cimentados por zeolitas (z) e carbonato (c). Textura esferulttica (es) também é observada (LN); 5 Tufo vitreo com as mesmas caracteristicas da figura 5, mostrando ainda fragmento de litoclasto vulcânico $(L)$ e textura esferultica (es) bem desenvolvida (LN); 6 - Tufo soldado: observam-se fragmentos de lava achatados, cujas terminaçōes em $Y$ se acham bem preservadas (LN); 7 - Olivina melaleucitito, destacando-se os microfenocristais de olivina $(O L)$ e flogopita (F1) corroldos imersos em matriz com piroxênio, leucita, perovskita e titanomagnetita (?). Notar duas gerações de flogopita (F1 e F2) e alteração da olivina para serpentina (S). (LN); 8 - Melaleucitito em que microfenocristais de clinopiroxênio se acham imersos em matriz com piroxênio, leucita, perovskita e minerais opacos. Notar a zonação e a alteração diferenciada dos clinopiroxênios. (LN); 9 - Fenocristal poiquilitico de flogopita, em flogopita melaleucitito, englobando diminutos cristais de perovskita, clinopiroxênio, leucita e minerais opacos. 
10

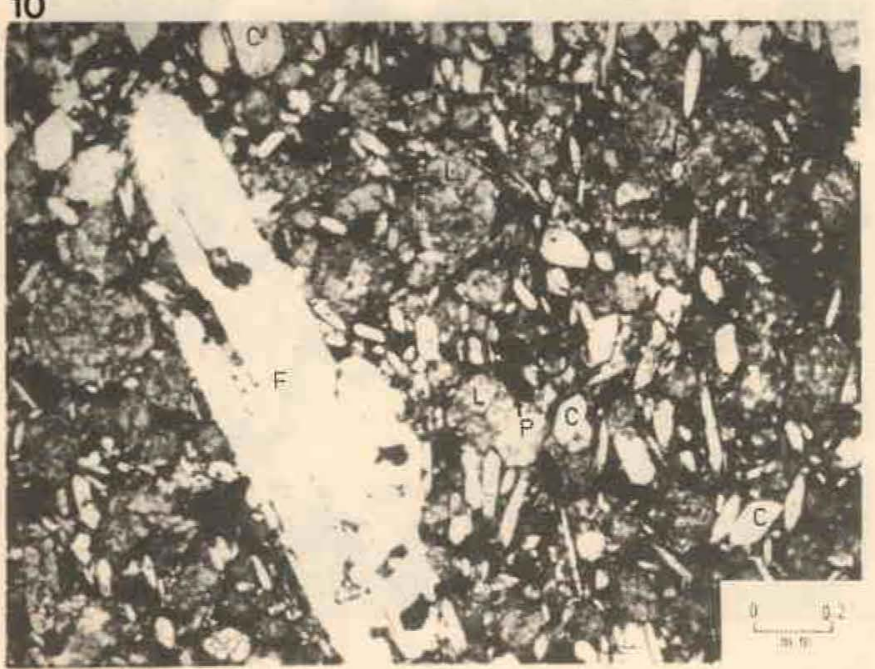

12

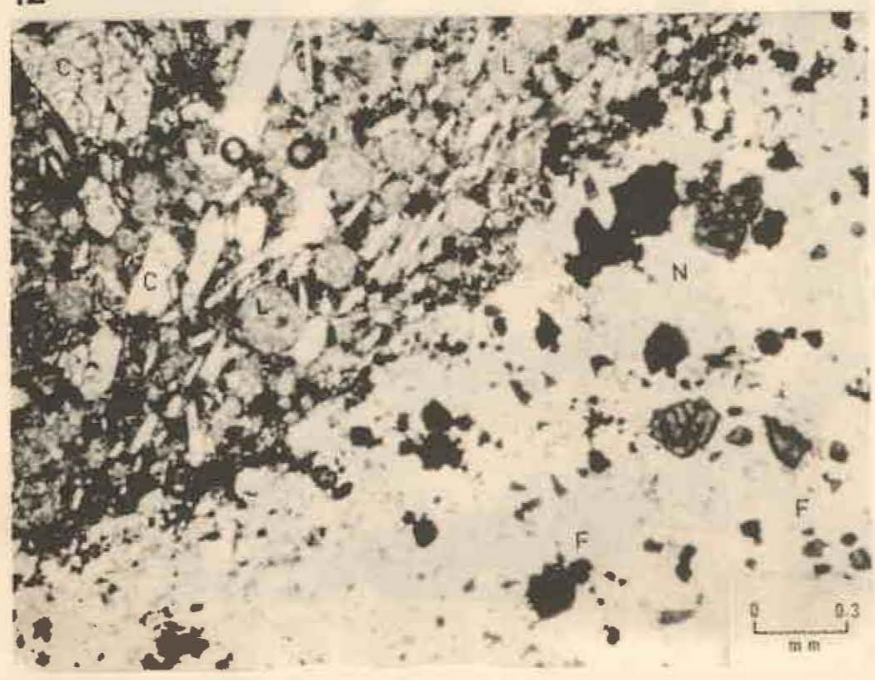

14

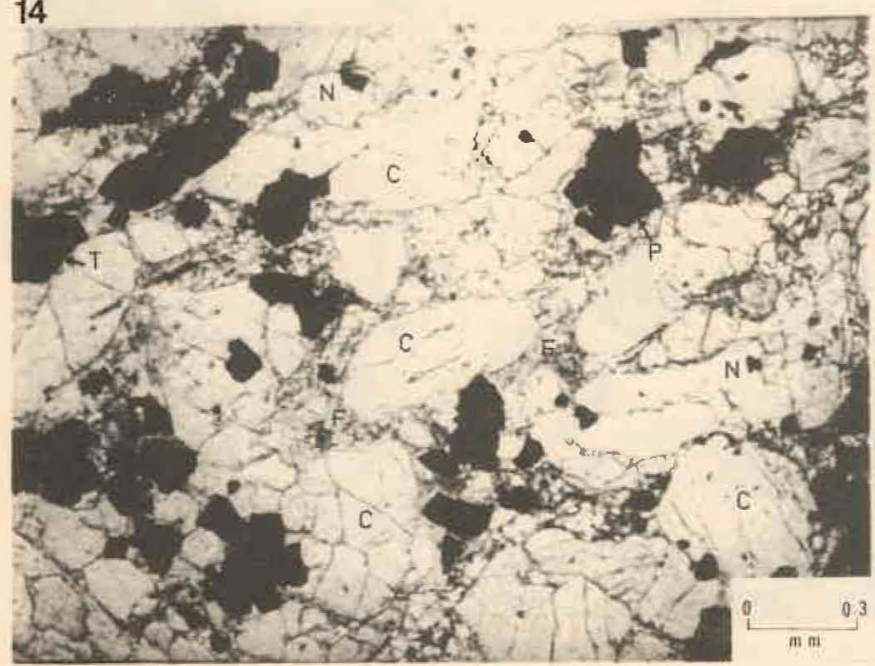

11
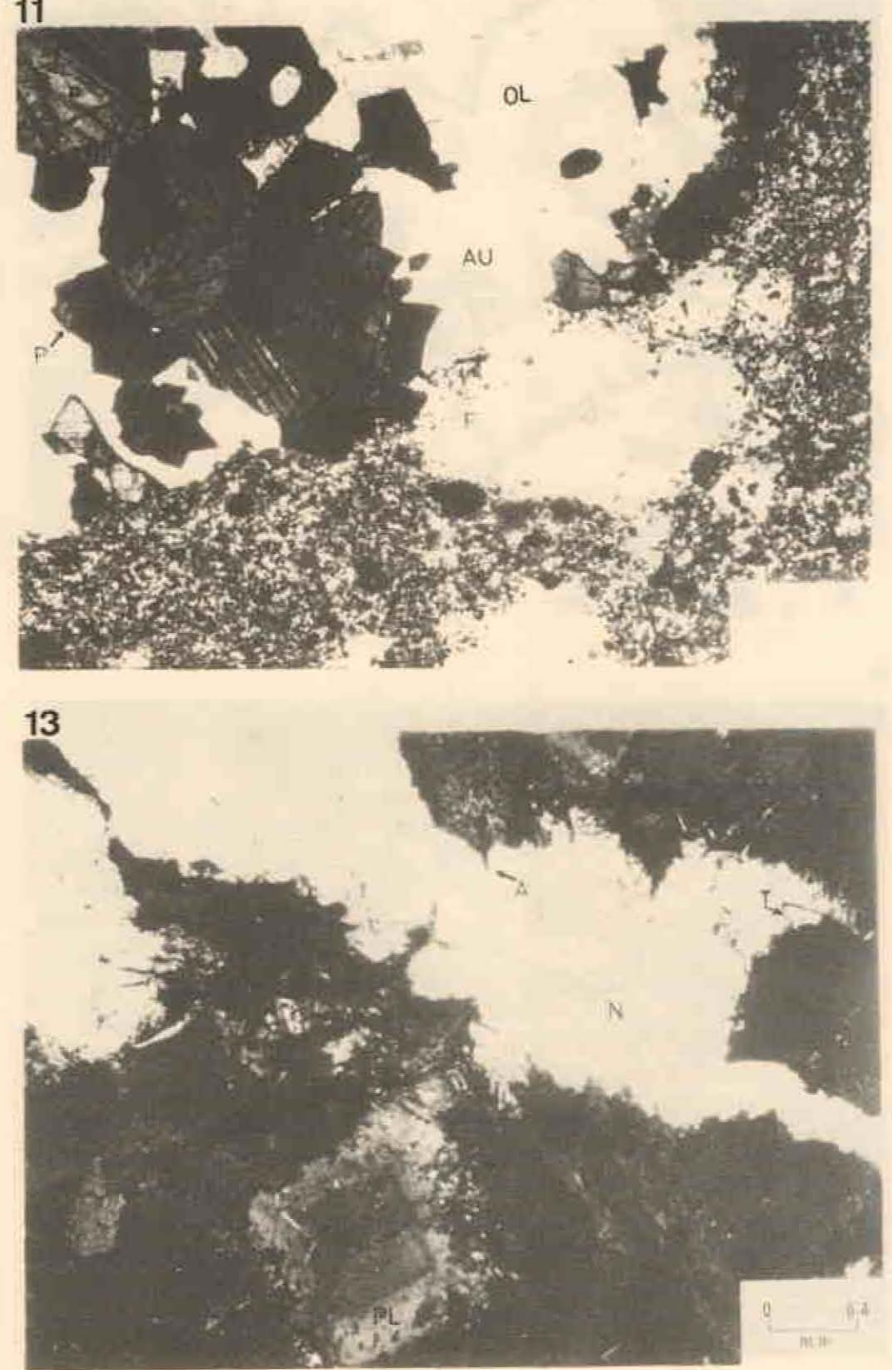

15

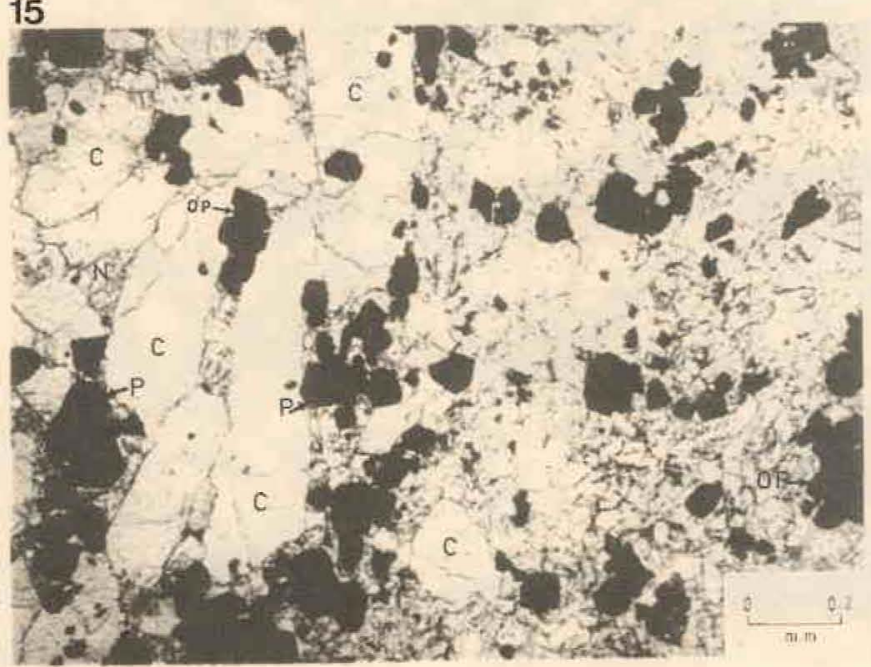

Prancha 2 - Fotomicrografias. 10 - Flogopita melaleucitito em que microfenocristais de flogopita $(F)$ se acham imersos em matriz fina com leucita $(L)$, clinopiroxênio $(C)$, perovskita $(P)$ e minerais opacos $(L N) ; 11$ - Xenólito constitúto por olivina $(O L)$, augita $(A U)$, perovskita $(P)$, leucita, nefelina e minerais opacos no interior de olivina melaleucitito. Notar microfenocristais de olivina $(O)$ da matriz transformando-se para agregados de flogopita $(F)(L P) ; 12$ - Xenólito constituldo por flogopita $(F)$, nefelina $(N)$, perovskita, augita e minerais opacos em melaleucitito formado por clinopiroxênio $(C)$, leucita $(L)$, perovskita e minerais opacos (LN); 13 Sienito composto por plagioclásio sódico $(P L)$, às vezes zonado, nefelina $(N)$; titanita $(T)$ e aegirina $(A)$ como finas agulhas. $(L P) ; 14$ - Álcali-piroxenito constitufdo por clinopiroxénio $(C)$, perovskita $(P)$, titano-magnetita? $(T)$, flogopita $(F)$ além de nefelina $(N)$, zeólita e apatita. $(L N)$; 15 - Álcali-piroxenito com clinopiroxênio $(C)$, perovskita $(P)$, minerais opacos $(O P)$ e nefelina $(N)$ 
Tabela 1 - Caracterização qualitativa dos tipos petrográficos encontrados entre as rochas igneas da região de Lagoa Formosa: produtos de alteraçâo (zeblitas, carbonatos, talco, bowlingita, aegirina, bxidos e hidroxxidos de ferro) não estão computados. Os números entre parênteses na primeira coluna indicam o número de amostras analisadas. Sĺmbolos: - 5\%; -- 5\% a $10 \%$; -- 10\% a 20\%; ---- 20\% a 30\%; ----- 40\% a 50\%; -..-- 50\%; LE, leucita; AUGIDIOP, augitaldiopsídio; OL, olivina; FLOG, flogopita; PEROV, perovskita; PLAG, plagioclásio; NEF, nefelina; K-FELD, feldspato potássico; BIOT, biotita; AEG, aegirina; MIN OP, minerais opacos. Discussão no texto

\begin{tabular}{|c|c|c|c|c|c|c|c|c|c|c|c|}
\hline Rocha $\quad$ Mineral & LE & $\begin{array}{l}\text { AUG/ } \\
\text { DIOP }\end{array}$ & OL & FLOG & PEROV & PLAG & NEF & K-FELD & BIOT & AEG & $\begin{array}{l}\text { MIN } \\
\text { OP }\end{array}$ \\
\hline 1. Melaleucitito (8) & $\cdots$ & $\cdots$ & - & - & - & & & & & & - \\
\hline 2. Olivina melaleucitito (12) & $\cdots$ & $-\cdots--$ & -- & - & - & & & & & & - \\
\hline 3. Flogopita melaleucitito (10) & - & -..--. & - & -. & - & & & & & & -- \\
\hline 4.Basalto (2) & & -...-- & & & & $-\cdots$ & & & & & - \\
\hline 5. Sienito gnáissico (1) & & & & & & --- & - & $\cdots$ & -- & & - \\
\hline 6. Sienito (1) & & -. & & & & --- & -. & $\cdots$ & & & - \\
\hline 7. Álcali-piroxenito (2) & & --.--- & & -- & -- & & - & & & & - \\
\hline
\end{tabular}

Ao microscópio, apresenta textura seriada, dada pela variação de tamanho dos cristais de plagioclásio, augita (?) e magnetita. Os cristais de plagioclásio apresentam-se com zonação freqüente, apesar de pouco pronunciada. Os microfenocristais de clinopiroxênio podem estar maclados e zonados, e, não raramente, formam aglomerados de cristais, aos quais se associa a magnetita. Esta cltima mostra-se invariavelmente corroída.

Sienitos $\quad \mathrm{Na}$ área em questão só foram encontradas quatro amostras de sienito, todas como blocos de brecha piroclástica com tamanho variável entre 2 e $10 \mathrm{~cm}$, em locais bem afastados entre si. Devido ao intemperismo, s6 duas delas foram estudadas. A primeira tem textura maciça, granulação média e cor creme-esverdeada. Sua mineralogia é representada por plagioclásio sódico com forma tipicamente rômbica e zonado, augita (?) fortemente alterada, nefelina com aspecto turvo, aegirina com aspecto feltroso e titanita (Fotomicrografia 13).

A segunda tem um aspecto gnáissico e seu único mineral ferromagnesiano $\varepsilon$ biotita, que se encontra orientada e fortemente oxidada. É ainda composta por cristais de microclínio e nefelina límpidos e plagioclásio sódico parcial ou totalmente argilizado. Titanita $\varepsilon$ rara. Esta rocha pode ter-se originado por processo de fenitização potássica (Le Bas 1977) mas não há dados conclusivos a esse respeito.

DISCUSSÃO Com base em descrições macroscópica e microscópica, as rochas da região de Lagoa Formosa (MG) foram caracterizadas como melaleucititos, olivina melaleucititos, flogopita melaleucititos e, subordinadamente, ácali-piroxenito, basalto e sienito.

Os dados existentes até o momento não permitem uma definição dessa suíte como Lamproítica ou Kamafugítica (Sahama, in Sфrensen, 1974). Conforme já se discutiu anteriormente, a ausência de $\mathrm{K}$-richterita, priderita e wadeíta afasta-a dos lamprótos. Mas não se deve descartar a hipótese de que, em algumas amostras, os minerais aciculares considerados aegirina sejam, na realidade, K-richterita. Seu pequeno tamanho e quantidade torna impossível uma caracterização segura pelos métodos utilizados. Por outro lado, sua relação com os Kamafugitos $\varepsilon$ estreita, mas a principal dificuldade para caracte-

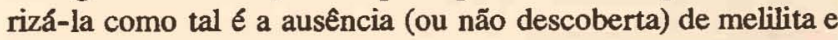
kalsilita.

Desse modo, uma melhor definição da filiação das rochas em questão só será possível após estudos litogeoquímicos sistemáticos, já em andamento.

Agradecimentos Este trabalho foi realizado com auxflio do CNPq, Processo no 401753/84, e faz parte de um projeto mais amplo do qual participam, ainda, os seguintes professores da UFMG: Antônio Celso C. Fogaça, Patrícia Barbosa A. Sgarbi e Geraldo Norberto C. Sgarbi. Agradecemos especialmente a participação do discente Miguel Pitella e a colaboração da professora Selma Maria Fernandes, da UFOP, que gentilmente analisou as zeólitas através de difraçāo de raios $\mathrm{X}$, e a Rosália Aparecida Santos, pela datilografia.

\section{REFERÊNCIAS BIBLIOGRÁFICAS}

BARBOSA, O. 1936. Notícia sobre estudos geológico-econômicos em Patos. Rev. Esc. Minas, ano 1(5-6):165-169.

BARBOSA, O.; BRAUN, O.P.G.; DYER, R.C. \& CUNHA, C.A.B.R. 1970. Geologia da Região do Triângulo Mineiro. Rio de Janeiro, DNPM/DFPM. 140 p. (Boletim 136).

COSTA, M.T. \& SAD, J.H.G. 1968. O cretáceo em Minas Gerais. In: CONGR. BRAS. GEOL., 22, Belo Horizonte, 1968. Res. Com... Belo Horizonte, SBG.

COUTINHO, J.M.V.; COIMBRA, A.M.; NETO, M.B. \& ROCHA, G.A. 1982. Lavas alcalinas analcimíticas associadas ao Grupo Bauru $(\mathrm{Kb})$ no Estado de São Paulo, Brasil. In: CONGR. LATINOAMERICANO GEOL., 5, Buenos Aires, 1982. Actas..., Buenos Aires. v 2: 185-195.
ESCHWEGE, W.L. von 1979. Pluto Brasiliensis. Belo Horizonte, Ed. Itatiaia e Sâo Paulo, EDUSP. 2v.

GASPAR, J.C. \& DANNI, I.C.M. 1979. Analcima nas rochas vulcânicas de Santo Antônio da Barra, Goiás, e suas possíveis implicações petrogenéticas. Recife, Bol. Mineral. (6):41-49.

GUIMARÃES, D. 1927. O diamante no Estado de Minas Gerais: Brasil. Serv. Geol. Miner. 46 p. (Boletim 24).

JAQUES, A.L.; LEWIS, J. D.; SMITH, C.B.; GREGORY, G.P., FERGUSON, J.; CHAPPELL. B.W.; MCCULLOCH. M.T. 1984. The diamond-bearing ultrapotassic (lamproitic) rocks of the West Kimberley Region. Western Austrália. In: KORN PROBS J. ed. Kimberlites l: kimberlites and Related Rocks. Amsterdam, Elsevier. p. 225-254. 
LADEIRA, E.A. \& BRITO, O.E.A. de. 1968. Contribuição à Geologia do Planalto da Mata da Corda. In: CONGR. BRAS. GEOL., 22. Belo Horizonte, 1968: Anais... Belo Horizonte. SBG. v. 2. p. 181199.

LE BAS, M.J. 1977. Carbonatite-Nephelinite volcanism. London, Wiley. $347 \mathrm{p}$.

MORAES. L.C.: SEER. H. J.; FOGACA. A.C.C.: SGARBI, P.B.A.; SGARBI, G.N.C. 1986. Geologia das unidades cretácicas da área compreendida entre Lagoa Formosa e Carmo do Paranaíba, MG. In: CONGR. BRAS. GEOL. 34, Goiânia, 1986. Anais.... Goiânia, SBG. v. 1. p. 337-345.

RIMANN, E. 1917. A Kimberlita no Brasil. Ouro Preto, Esc. Minas. (An. Esc. Minas, Boletim 15).
SAHAMA. Th. G. 1974. Potassium-rich alkaline rocks. In: Srensen, H. ed. The alkaline rocks. John Wiley \& Sons. p. 96-108.

SEER, H.J., MORAES, L.C.; FOGAÇA, A.C.C. 1987. Faciologia e estruturação tectônica dos metassedimentos com diamictitos e jaspilitos da região de Lagoa Formosa - MG (Grupo Bambuí?). In: SIMP. GEOL. MINAS GERAIS, 4, Belo Horizonte, 1987. Anais..., Belo Horizonte, SBG. p. 199-213.

STRECKEISEN, A.L. 1967. Classification and nomenclature of igneous rocks. Neues Jb. Miner. Abh., 107:144-240.

MANUSCRITO 406 Recebido em 25 de novembro de 1986 Revisão aceita em 03 de novembro de 1987 